From the Department of Family Medicine and School of Nursing, College of Medicine and Hospital, National Taiwan University; and Department of Family Medicine, North Coast Jin-Shan Hospital, Taipei, Taiwan.

Submitted December 9, 2008; accepted February 18, 2009; published online ahead of print at www.jco.org on May 26,2009

Supported by National Science Council, Taiwan

Authors' disclosures of potential conflicts of interest and author contributions are found at the end of this article.

Corresponding author: Tai-Yuan Chiu, MD, MHSci, No. 7 Chung-Shan South Rd, Taipei, Taiwan; e-mail: tychiu@ ntuh.gov.tw.

The Acknowledgment and Appendix are included in the full-text version

of this article; they are available online at www.jco.org. They are not included in the PDF version (via Adobe ${ }^{\circledR}$ Reader ${ }^{\circledR}$ ).

() 2009 by American Society of Clinical Oncology

0732-183X/09/2724-3964/\$20.00

DOI: $10.1200 / J C O .2008 .21 .4643$

\title{
Prevailing Ethical Dilemmas in Terminal Care for Patients With Cancer in Taiwan
}

Tai-Yuan Chiu, Wen-Yu Hu, Hsien-Liang Huang, Chien-An Yao, and Ching-Yu Chen

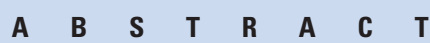

\section{Purpose}

The study aimed to investigate prevailing ethical dilemmas in terminal care for patients with cancer nationwide and identify related factors after the enactment of the Natural Death Act in Taiwan.

\section{Methods}

This multicenter study surveyed 800 physicians and nursing staff of oncology wards and hospices through a set questionnaire. A total of 505 respondents $(63.1 \%)$ who had taken care of patients with terminal cancer were analyzed.

\section{Results}

The most frequently encountered ethical dilemmas were truth-telling (mean $\pm \mathrm{SD}=1.30 \pm 0.63$; range [never, occasional, often], 0 to 2 ) and place of care (1.19 \pm 0.69$)$, both of which were related to communication issues. Dilemmas related to clinical management were artificial nutrition and hydration (1.04 \pm 0.66$)$ and use of antimicrobial agents $(0.94 \pm 0.70)$. Logistic regression analyses revealed that positive attitudes about the Natural Death Act was negatively related to the extent of ethical dilemmas (odds ratio, $0.426 ; 95 \% \mathrm{Cl}, 0.256$ to 0.710$]$.

\section{Conclusion}

The enactment of the Natural Death Act in Taiwan would contribute to improving the quality of end-of-life care, which suggests that this kind of law should be adopted in other countries. Educating cancer care professionals in building positive beliefs toward the act is strongly encouraged.

\section{J Clin Oncol 27:3964-3968. (C) 2009 by American Society of Clinical Oncology}

\section{INTRODUCTION}

The process of caring for patients with cancer is continuous, and supportive care provided by cancer care professionals is well recognized. As cancer ranks first among the 10 leading causes of death in Taiwan, the number of patients with terminal cancer has continued to increase, and palliative care is being advocated as an ideal model for their care. However, in clinical care for patients with cancer, especially those in the terminal stage, difficulties in decision making and ethical conflicts are frequently encountered. ${ }^{1,2}$

Previous studies report that the most frequently encountered ethical dilemmas in the United States ${ }^{3}$ and United Kingdom ${ }^{4}$ include predicting survival of the terminally ill; truth-telling; the principle of hydration and nutrition support; the use of antibiotics; and treatment of hypercalcemia, uremia, abnormal serum sugar level, and abnormal liver function. Despite cultural differences, our team conducted a pilot survey in a palliative care unit in Taiwan in 1998, which re- vealed that place of care, truth-telling, and artificial hydration and nutrition were ranked first among all dilemmas. ${ }^{5}$ The lack of solutions to some of these ethical dilemmas and the lack of ethical training inevitably impedes the pursuit of better quality of care.

Taiwan is the first Asian country to have a Natural Death Act, legalized in 2000 (see Appendix, online only), and the act states that dying patients or their families have the right to refuse unnecessary medical management that only prolong the agony stage. The Natural Death Act provides medical personnel a legal basis to make medical decisions in accordance with the will of patients. ${ }^{6}$ With this backdrop, this study aimed to investigate the most frequently encountered ethical dilemmas of all cancer care professionals in Taiwan after the enactment of the Natural Death Act and explore related factors. The results can help government and medical care systems design effective interventions to help medical staffs improve their decision making and promote quality of end-of-life care. 


\section{METHODS}

\section{Design}

This study is a cross-sectional survey using the clustering sampling method and a well-structured questionnaire, which was mailed to potential respondents from March 2005 to August 2006. A second questionnaire was mailed to those who did not return the reply postcard 2 weeks after the initial mailing. Return and completion of the questionnaire represented the participation consent.

\section{Subjects}

Targeted participants included health care professionals such as doctors and nurses working at oncology wards or palliative care units where terminal care might be provided in Taiwan. Eligible respondents were recruited from nationwide organizations, including the Hospice Foundation of Taiwan, Chinese Oncology Society in Taiwan, Oncology Nursing Society of Taiwan, and Taiwan Academy of Hospice Palliative Medicine, and the members in these organizations include all the cancer care professionals who might actively provide terminal care in Taiwan as a result of medical care regulations and the Taiwan National Health Insurance system. After exclusion of overlapping names, the total sample population contained 350 doctors and 450 nurses. Before the study was conducted, the design of study and subjects selection were approved by the ethical committee in the hospital and National Science Council in Taiwan.

\section{Questionnaire}

The five-part questionnaire was administered to all participants. The five parts included questions on demography, knowledge in palliative care, knowledge in the Natural Death Act, attitudes about the Natural Death Act, and frequency of ethical dilemmas. The questionnaire was pretested for face validity by a panel composed of 10 physicians and nurses who were all experienced in the care of the terminally ill. Jury opinion of five experts also tested the content validity. Each item was evaluated on a scale of 1 (low) to 5 (high) for clarity and relevance to clinical practice, and items with a rating of at least 4 were included.

Demographic characteristics included sex, age, education, profession, religion, and professional experience. The other four parts included the following:

Knowledge in palliative care. This measure evaluated the philosophy and principle of hospice and palliative care, as well as practical knowledge (12 items). The main reference was the palliative quiz for nursing originally developed by Ross et al. ${ }^{7}$ All of the items were grounded on real experiences of the investigators. The scoring system of this scale was "true" (1) and "false/unknown" (0). A preliminary survey was conducted to establish the validity and reliablility of the questionnaire during the period 2003-2004.

Knowledge in the Natural Death Act. Designed with careful scrutiny of the Natural Death Act, this part included important regulations in the whole 15 articles of the law after expert panel discussion. The measure had 22 items and scored using "true" (1) and "false/unknown" (0). The Kuder-Richardson Formula 20 assessed the internal consistency of this new measure and showed a coefficient of 0.8138 .

Attitudes (belief and evaluation) about the Natural Death Act. This part examined the perception of professionals regarding the advantages and disadvantages of the Natural Death Act. The scoring system was 5-point Likert Scale, from "strongly disagree or very unimportant" (1) to "strongly agree or very important" (5). Reverse scoring was used in the disadvantages section. Higher total attitude scores indicated more positive attitude regarding the law. Bartlett's test of sphericity was 4739.765 , significant value was 0.000 , and KaiserMeyer-Olkin test was 0.880 . The measure was therefore suitable for exploratory factor analysis.

The draft items were analyzed using principal component analysis followed by orthogonal varimax rotation. Attitudes were measured as "perception of benefits" and "perception of burdens." Cronbach $\alpha$ for these factors were 0.8739 and 0.8336 , respectively, showing that items contained in each factor could be used to test the same characteristic.

Frequency of ethical dilemmas. From literature review, a group of experts designed 11 items covering the most frequently encountered ethical dilemmas in the daily care of terminal patients. These dilemmas were graded on a 3-point scale as follows: 0 , never happened; 1, happened, occasionally; 2 , happened, often. Bartlett's test of sphericity was 1408.543 , significant value was 0.000 , and Kaiser-Meyer-Olkin test was 0.819 . The scale was therefore suitable for exploratory factor analysis.

The draft items were analyzed using principal component factor analysis followed by orthogonal varimax rotation. Two factors were extracted, and dilemmas frequency measure was reconstructed and named "issues of communication" and "issues of clinical care." Internal consistency was demonstrated with a Cronbach $\alpha$ coefficient of 0.7732 and 0.6827 , respectively.

\section{Statistical Analysis}

Data management and statistical analysis were performed using the SPSS 11.0 statistical software (SPSS, Chicago, IL). Frequency distributions described the demographic data and the distribution of each variable. Mean values and standard deviations (SDs) were used to analyze the degree of each variable in the knowledge of palliative care, knowledge of the Natural Death Act, belief and evaluation of the Natural Death Act, and frequency of ethical dilemmas. The $t$ test was used for the comparison of mean scores of those continuous variables between physicians and nurses groups.

Stepwise logistic regression analysis determined the relative values of the variables related to scores in the frequency of ethical dilemmas, including total scores and scores on issues of communication and issues of clinical care. Professionals who scored above and below the mean \pm SD scores were designated as high- and low-scoring groups, respectively. A $P$ value less than .05 was considered statistically significant.

\section{RESULTS}

\section{Demographic Characteristics}

Of the 800 professionals to whom the questionnaires were mailed, 614 responded. After deducting incomplete questionnaires $(n=22)$ and those considered not having the experience of caring for terminally ill patients $(\mathrm{n}=87), 505$ were included in the final analysis. Background information of the participants is summarized in Table 1.

\section{Variables Related to Frequency of Ethical Dilemmas}

Table 2 shows possible factors related to the frequency of ethical dilemmas, including knowledge on palliative care and the Natural Death Act, and attitudes about the Natural Death Act.

The mean percentage of accurate responses to palliative care knowledge was $71.2 \%$ (range, $19.2 \%$ to $99.4 \%$ ). Accurate answers to the philosophy and principles, and clinical management of palliative care were $82.2 \%$ and $75.5 \%$, respectively. Accuracy was less than $60 \%$ for the three items, including psychological support (two items) and management of pain (one item). Physicians groups had significantly higher total scores in palliative care knowledge and the scores of philosophy and principles.

Regarding knowledge in the Natural Death Act, the mean percentage of accurate responses was $64.9 \%$ (range, $12.3 \%$ to $98.4 \%$ ). There were seven items with an accuracy more than $90 \%$ and nine items with accuracy less than $60 \%$. Lower scoring items in this scale included the following: "the patient may rescind his or her will of consent at any time, by written request, either himself or herself or through a designated agent" (mean score $=0.12$ ); "this Act is enacted for the purpose of authorizing the physician not to administer cardiopulmonary resuscitation" (mean score $=0.37$ ); and "The family referred to in Articles of this Act means the family present in the medical institution during the administration of hospice/palliative care" (mean score $=0.38)$. 


\begin{tabular}{|c|c|c|}
\hline Variable & No. & $\%$ \\
\hline \multicolumn{3}{|l|}{ Sex } \\
\hline Male & 164 & 32.5 \\
\hline Female & 341 & 67.5 \\
\hline \multicolumn{3}{|l|}{ Age, years } \\
\hline Average & \multicolumn{2}{|c|}{35.27} \\
\hline SD & \multicolumn{2}{|c|}{9.192} \\
\hline \multicolumn{3}{|l|}{ Current workplace } \\
\hline Oncology ward & 163 & 32.3 \\
\hline Internal medicine ward & 65 & 12.9 \\
\hline Surgical ward & 38 & 7.5 \\
\hline Emergency department or intensive care units & 26 & 5.1 \\
\hline Hospice ward & 108 & 21.4 \\
\hline Pediatric ward & 6 & 1.2 \\
\hline Long-term care institution & 7 & 1.4 \\
\hline Other & 92 & 18.2 \\
\hline \multicolumn{3}{|l|}{ Profession } \\
\hline Physician & 196 & 38.8 \\
\hline Nurse & 309 & 61.2 \\
\hline \multicolumn{3}{|l|}{ Clinical experience, years } \\
\hline Average & \multirow{2}{*}{\multicolumn{2}{|c|}{$\begin{array}{c}10.667 \\
7.7140\end{array}$}} \\
\hline SD & & \\
\hline \multicolumn{3}{|l|}{ Religion } \\
\hline Not specified & 168 & 33.3 \\
\hline Common traditional belief & 102 & 20.2 \\
\hline Buddhist & 114 & 22.6 \\
\hline Taoist & 27 & 5.3 \\
\hline Christian & 70 & 13.9 \\
\hline Catholic & 9 & 1.8 \\
\hline I-Kuan Tao & 13 & 2.6 \\
\hline Other & 2 & 0.4 \\
\hline \multicolumn{3}{|l|}{ Personal importance of religion } \\
\hline Not at all & 5 & 1.0 \\
\hline Not important & 27 & 5.3 \\
\hline Fairly important & 117 & 23.2 \\
\hline Important & 256 & 50.7 \\
\hline Very important & 100 & 19.8 \\
\hline
\end{tabular}

The mean score of attitudes about the Natural Death Act of total respondents, physicians group, and nurses group were 152.48 (SD, 12.38; range, 40 to 200), 151.93 (SD, 12.28), and 152.82 (SD, $13.15)$ respectively. There were no significant differences between physicians and nurses on the mean score of attitudes about the Natural Death Act, and the two subconcepts of attitudes toward the Natural Death Act included "perception of benefits" and "perception of burdens."

\section{Frequency of Ethical Dilemmas}

The type and frequency scores of ethical dilemmas encountered are shown in Table 3. The items were ranked by the total scores (with their respective mean values) as follows: truth-telling $(1.30 \pm 0.633)$, place of care $(1.19 \pm 0.688)$, and alternative treatments $(1.06 \pm 0.686)$. All of these were related to issues of communication. Meanwhile, dilemmas related to issues of clinical care were ranked as artificial nutrition and hydration $(1.04 \pm 0.658)$, use of antimicrobial agents $(0.94 \pm 0.699)$, and palliative sedation $(0.77 \pm 0.706)$. Stratified analyses were performed on the ethical dilemmas of physicians, nurses, and different physicians' groups, including those working in the oncology ward and the hospice ward, and the results demonstrated that truth-telling, place of care, artificial hydration and nutrition, and use of antibiotics still had higher scores in the two factors of ethical dilemmas.

\section{Important Predicting Variables}

Results of stepwise logistic regression analysis revealed that the higher the scores on attitudes about the Natural Death Act, the lower the probability of being in the high-scoring group in total scores of the frequency of ethical dilemmas (odds ratio $[\mathrm{OR}]=0.426$; Table 4).

Further analysis for significant predicting variables in the subconcepts of scores in the frequency of ethical dilemmas showed that the more the clinical experiences $(\mathrm{OR}=9.969)$ and higher scores in knowledge of palliative care $(\mathrm{OR}=0.945)$, the lower the probability of being in the high-scoring group in ethical dilemmas related to issues of clinical management. Moreover, the greater the positive attitude about the Natural Death Act $(\mathrm{OR}=0.411)$, the lower the probability of being in the high-scoring group in ethical dilemmas related to issues of communication.

\section{DISCUSSION}

This study is one of the first nationwide surveys that focused on ethical dilemmas of health professionals in their daily care of patients with terminal cancer. Because Taiwan's Natural Death Act is the first such law enacted in an Asian country, this study has become even more relevant.

\begin{tabular}{|c|c|c|c|c|c|c|c|c|}
\hline \multirow[b]{2}{*}{ Variable } & \multicolumn{2}{|c|}{ Total } & \multicolumn{2}{|c|}{ Physicians } & \multicolumn{2}{|c|}{ Nurses } & \multirow[b]{2}{*}{$P^{*}$} & \multirow[b]{2}{*}{ Range } \\
\hline & Mean & SD & Mean & SD & Mean & SD & & \\
\hline Knowledge of palliative care & 8.54 & 1.60 & 8.81 & 1.57 & 8.38 & 1.60 & .003 & $0-12$ \\
\hline Philosophy/principles & 3.98 & 0.91 & 4.30 & 0.79 & 3.78 & 0.93 & $<.001$ & $0-6$ \\
\hline Clinical management & 4.56 & 1.137 & 4.51 & 1.25 & 4.60 & 1.04 & .347 & $0-6$ \\
\hline Knowledge of the Natural Death Act & 14.29 & 3.86 & 15.53 & 3.99 & 13.50 & 3.56 & $<.001$ & $0-22$ \\
\hline Attitudes about the Natural Death Act & 152.48 & 12.81 & 151.93 & 12.28 & 152.82 & 13.15 & .446 & $40-200$ \\
\hline Perception of benefits & 79.50 & 8.63 & 79.07 & 7.96 & 79.77 & 9.04 & .378 & $18-90$ \\
\hline Perception of burdens & 72.98 & 7.93 & 72.86 & 7.89 & 73.06 & 7.96 & .785 & $22-110$ \\
\hline
\end{tabular}




\begin{tabular}{|lcccr}
\hline \multicolumn{5}{c}{ Table 3. Frequency of Ethical Dilemmas* $(n=505)$} \\
\hline \multicolumn{1}{c}{ Variable } & Mean & SD & $\begin{array}{c}\text { Group } \\
\text { Rank }\end{array}$ & $\begin{array}{r}\text { Total } \\
\text { Rank }\end{array}$ \\
\hline Issues of clinical management & 4.52 & 2.680 & & \\
Artificial nutrition and hydration & 1.04 & 0.658 & 1 & 4 \\
Use of antimicrobial agents & 0.94 & 0.699 & 2 & 5 \\
Use of opioids & 0.57 & 0.704 & 5 & 10 \\
Use of corticosteroids & 0.49 & 0.584 & 6 & 11 \\
Blood transfusion & 0.72 & 0.585 & 4 & 9 \\
Palliative sedation & 0.77 & 0.706 & 3 & 8 \\
Issues of communication & 5.18 & 2.096 & & \\
Hospice referral & 0.81 & 0.733 & 5 & 7 \\
Place of care & 1.19 & 0.688 & 2 & 2 \\
Truth-telling & 1.30 & 0.633 & 1 & 1 \\
Alternative treatment & 1.06 & 0.686 & 3 & 3 \\
Euthanasia & 0.83 & 0.610 & 4 & 6 \\
\hline
\end{tabular}

Abbreviation: SD, standard deviation.

*Rated on a 3-point Likert-type scale of "never happened" (0), "happened, occasionally" (1), and "happened, often" (2).

In this study, truth-telling ranks first among all ethical dilemmas. In the study by $\mathrm{Hu}$ et $\mathrm{al},{ }^{8}$ factors such as "unable to manage patient's emotional reactions," "truth-telling of terminal cancer means medical failures," and "patients will be sad and commit suicide" influence the decision of truth-telling. As a result, medical staff choose to inform only the families, not the patient, regarding the disease status. This nondisclosure results in much psychological stress owing to the conflict involving the principle of autonomy and shared decision making. ${ }^{9-11}$ To solve these barriers and improve the quality of end-oflife care, patients must be given enough time to reflect on their sickness, receive information based on their expectations, receive compassionate support, communicate with their families, and be taught coping strategies regarding emotional reactions. ${ }^{12-14}$

Dilemma of place of care is also frequently encountered, not only in hospice wards but also in general wards. The gradual and inevitable decline of physical function and dependence on others' care make the discharge planning of terminal patients burdensome. Meanwhile, discrepancies between the preference of having terminal care until death at home and the actual place of dying have been reported. ${ }^{15-17}$ In Taiwan, a previous study reveals that the inability to manage emergency medical conditions, feeling of safety in the hospital, and insufficient number of caregivers are variables that influence the place of dying. ${ }^{18}$ Health professionals also encounter the limitation set by medical insurance companies and deficiencies in the patients' social support. To accomplish the patients' desire of a peaceful death at home, health care providers should have adequate communication skills, provide home care programs with effective referral systems, and continuously educate patients and family on care knowledge. ${ }^{19-21}$

With respect to ethical dilemmas related to issues of clinical care, artificial nutrition and hydration has the highest influence. Health professionals have markedly divergent attitudes regarding whether artificial nutrition and hydration can relieve symptoms of dehydration or merely increase the burden of patients with terminal cancer. ${ }^{22-24}$ Morita et $\mathrm{al}^{25}$ point out that additional supplementation of artificial nutrition and hydration not only causes limb edema or pulmonary effusion but require placement of invasive catheters. However, medical personnel still consider these to be the minimum standard of care, and not providing artificial nutrition and hydration means medical failure. To help make appropriate decisions, well-designed research aimed at determining the most adequate requirements for hydration and nutrition in terminal patients is warranted. Continuous discussion with patients to respect their will and autonomy is also important. ${ }^{26}$

Difficulty in prescribing antimicrobial agents is also common in the current investigation. As a result of declining immunity of terminal patients, several concerns should be addressed, including the emergence of resistant pathogens, the expensive costs of second- or third-line antibiotics, the capacity of antimicrobials to control symptoms, and the possibility of increasing physical burden with delay of dying process. ${ }^{27,28}$ Therefore, antimicrobial agents should be regarded as other life-sustaining treatments for end-of-life care, and physicians should judge their use carefully based on individualized and comprehensive assessment. ${ }^{29-31}$

In this study, positive belief in the Natural Death Act is the major variable for the overall ethical dilemma scores and for issues of communication. Health professionals can be more confident in decision making and have less difficulty in daily care when they believe that laws can benefit medical practice. On this basis, by elevating the positive belief toward the Natural Death Act and helping medical staff members perceive the benefits of the law, the quality of care can be improved. Regarding issues of clinical care, the results suggest that with increasing clinical experiences and accumulating knowledge toward the Natural Death Act, there will be fewer difficulties in clinical management. Moreover, from these findings, it is important to enhance the medical staffs' clinical experiences through effective ways, such as providing a good education system and helping them relieve terminal care stress. At the same time, continuous education on the law will enable health care providers to be confident in their clinical judgment and decrease fears of medical dispute.

\begin{tabular}{|c|c|c|c|c|c|}
\hline \multicolumn{6}{|l|}{ Total scores } \\
\hline \multicolumn{6}{|l|}{ Submodel 1: Issues of clinical management } \\
\hline Years of clinical experiences & -0.032 & 0.014 & 0.969 & .023 & 0.943 to 0.996 \\
\hline Knowledge of the Natural Death Act & -0.056 & 0.028 & 0.945 & .044 & 0.895 to 0.998 \\
\hline
\end{tabular}

Abbreviations: $\beta$, normalized beta coefficient; OR, odds ratio. 
This study has some limitations. First, the response rate is only $63.1 \%$, and generalization to nonrespondents may be of some concern. In addition, even though the study is a nationwide survey, influencing factors of ethical dilemmas, including different cultural background and value of life and death, must be taken into account. Because Confucian culture predominates in Taiwan, the findings here should be applied to other countries with modification.

In conclusion, cancer care professionals still frequently encounter ethical dilemmas in caring for the terminally ill in Taiwan. Positive attitudes and greater knowledge in the Natural Death Act may help to solve these dilemmas. Continuing education that focuses on the knowledge and application of the Natural Death Act is essential to improve attitudes toward these ethical dilemmas. The enactment of the Natural Death Act in Taiwan would be helpful in improving the quality of end-of-life care, and this kind of law should be adopted in other countries. It is necessary to build positive beliefs toward the act during cancer care professional development.
AUTHORS' DISCLOSURES OF POTENTIAL CONFLICTS OF INTEREST

The author(s) indicated no potential conflicts of interest.

\section{AUTHOR CONTRIBUTIONS}

Conception and design: Tai-Yuan Chiu, Wen-Yu Hu, Hsien-Liang Huang, Ching-Yu Chen

Provision of study materials or patients: Tai-Yuan Chiu, Wen-Yu Hu, Chien-An Yao

Collection and assembly of data: Tai-Yuan Chiu, Wen-Yu Hu, Hsien-Liang Huang

Data analysis and interpretation: Tai-Yuan Chiu, Wen-Yu Hu, Hsien-Liang Huang, Ching-Yu Chen

Manuscript writing: Tai-Yuan Chiu, Hsien-Liang Huang, Wen-Yu Hu Final approval of manuscript: Tai-Yuan Chiu, Wen-Yu Hu, Hsien-Liang Huang

\section{REFERENCES}

1. Wanzer SH, Federman DD, Adelstein SJ, et al: The physician's responsibility toward hopelessly ill patients: A second look. N Engl J Med 320:844849, 1989

2. Quill TE, Lo B, Brock DW: Palliative options of last resort: A comparison of voluntarily stopping eating and drinking, terminal sedation, physicianassisted suicide, and voluntary active euthanasia. JAMA 278:2099-2104, 1997

3. Kinzbrunner BM: Ethical dilemmas in hospice and palliative care. Support Care Cancer 3:28-36, 1995

4. Finlay I: Difficult decisions in palliative care Br J Hosp Med 56:264-267, 1996

5. Chiu TY, Hu WY, Cheng SY, et al: Ethical dilemmas in palliative care: A study in Taiwan. J Med Ethics 26:353-357, 2000

6. Tsai LY, Lee MY, Lai YL, et al: Practical effects of educating nurses on the Natural Death Act. Support Care Cancer 13:232-238, 2005

7. Ross MM, McDonald B, McGuinness J: The palliative care quiz for nursing (PCON): The development of an instrument to measure nurses' knowledge of palliative care. J Adv Nurs 23:126-137, 1996

8. Hu WY, Chiu TY, Chuang RB, et al: Solving family-related barriers to truthfulness in cases of terminal cancer in Taiwan: A professional perspective. Cancer Nurs 25:486-492, 2002

9. Panagopoulou E, Mintziori G, Montgomery A, et al: Concealment of information in clinical practice: Is lying less stressful than telling the truth? J Clin Oncol 26:1175-1177, 2008

10. Rockwell LE: Truthtelling. J Clin Oncol 25: 454-455, 2007
11. Surbone A: Telling the truth to patients with cancer: What is the truth? Lancet Oncol 7:944-950, 2006

12. Helft PR: Necessary collusion: Prognostic communication with advanced cancer patients. J Clin Oncol 23:3146-3150, 2005

13. Fallowfield $L$, Jenkins V: Communicating sad, bad, and difficult news in medicine. Lancet 363:312319, 2004

14. Cheng S, Hu W, Liu W, et al: Good death study of elderly patients with terminal cancer in Taiwan. Palliat Med 22:626-632, 2008

15. Gomes B, Higginson IJ: Factors influencing death at home in terminally ill patients with cancer: Systematic review. BMJ 332:515-521, 2006

16. Burge F, Lawson B, Johnston G: Trends in the place of death of cancer patients, 1992-1997. CMAJ 168:265-270, 2003

17. Lin HC, Lin CC: A population-based study on the specific locations of cancer deaths in Taiwan, 1997-2003. Support Care Cancer 15:1333-1339, 2007

18. Hu WY, Chiu TY, Cheng YR, et al: Why Taiwanese hospice patients want to stay in hospital: Health-care professionals' beliefs and solutions. Support Care Cancer 12:285-292, 2004

19. Liu WJ, Hu WY, Chiu YF, et al: Factors that influence physicians in providing palliative care in rural communities in Taiwan. Support Care Cancer 13:781-789, 2005

20. Yao CA, Hu WY, Lai YF, et al: Does dying at home influence the good death of terminal cancer patients? J Pain Symptom Manage 34:497-504, 2007

21. Munday $D$, Dale J: Palliative care in the community. BMJ 334:809-810, 2007

22. McCann RM, Hall WJ, Groth-Juncker A: Comfort care for terminally ill patients: The appropriate use of nutrition and hydration. JAMA 272:12631266, 1994

23. Chiu TY, Hu WY, Chuang RB, et al: Nutrition and hydration for terminal cancer patients in Taiwan. Support Care Cancer 10:630-636, 2002

24. Ke LS, Chiu TY, Lo SS, et al: Knowledge, attitudes, and behavioral intentions of nurses toward providing artificial nutrition and hydration for terminal cancer patients in Taiwan. Cancer Nurs 31:67-76, 2008

25. Morita T, Shima $Y$, Adachi I: Attitudes of Japanese physicians toward terminal dehydration: A nationwide survey. J Clin Oncol 20:4699-4704, 2002

26. Oh DY, Kim JH, Lee $\mathrm{SH}$, et al: Artificial nutrition and hydration in terminal cancer patients: The real and the ideal. Support Care Cancer 15:631-636, 2007

27. Ford PJ, Fraser TG, Davis MP, et al: Antiinfective therapy at the end of life: Ethical decisionmaking in hospice-eligible patients. Bioethics 19: 379-392, 2005

28. White PH, Kuhlenschmidt HL, Vancura BG, et al: Antimicrobial use in patients with advanced cancer receiving hospice care. J Pain Symptom Manage 25:438-443, 2003

29. D'Agata E, Mitchell SL: Patterns of antimicrobial use among nursing home residents with advanced dementia. Arch Intern Med 168:357-362, 2008

30. Fabiszewski KJ, Volicer B, Volicer L: Effect of antibiotic treatment on outcome of fevers in institutionalized Alzheimer patients. JAMA 263:31683172, 1990

31. Marcus EL, Clarfield AM, Moses AE: Ethical issues relating to the use of antimicrobial therapy in older adults. Clin Infect Dis 33:1697-1705, 2001 